\title{
Réplica a Luis Garagalza
}

\section{Replay to Luis Garagalza}

\author{
Verónica Volkow \\ Universidad Nacional Autónoma de México \\ Instituto de Investigaciones Filológicas \\ volkowfe@icloud.com \\ orcid.org/oooo-ooo3-2831-6464
}

Resumen: Se trata de una réplica a la ponencia de Luis Garagalza “Tras las huellas de Hermes: la hermenéutica simbólica como contribución a los estudios del imaginario", que intenta nivelar afirmaciones demasiado extremistas de la hermenéutica filosófica contemporánea, principalmente desde de la práctica filológica y desde la perspectiva de género latinoamericana. Si la hermenéutica contemporánea accede desde la filología a un estatus filosófico, aquí intentamos revisar si algunas de sus afirmaciones más radicales siguen siendo coherentes con la práctica filológica y desde la presente perspectiva de género. Hay afirmaciones extremas, como la de la cancelación de la validez de los métodos o la de que no existen hechos sino interpretaciones, que requieren un equilibro más sensato. Consideramos que se impone un trabajo de duelo respecto de la omnipotencia de los viejos métodos epistémicos, que no implica la cancelación de su orientadora validez, sino solo una conciencia de sus limitaciones. Este trabajo de duelo no debe implicar un rompimiento completo con los modelos pasados sino un despedirse de las expectativas no funcionales, pero también una recuperación de lo rescatable.

Palabras clave: hermenéutica contemporánea, Luis Garagalza, interpretación filológica, el duelo de los métodos epistémicos, hermenéutica y perspectiva de género, antifascismo

Abstract: This is a reply to a paper presented by Luis Garagalza, called: "Following the Steps of Hermes: The Symbolic Hermeneutics as a Contribution to the Imaginary Studies", which attempts to level overly extreme claims of contemporary philosophical hermeneutics, mainly from philological practice and from the Latin American gender perspective. If contemporary hermeneutics accesses a philosophical status through philology, here we try to review whether some of its most radical claims remain consistent with philological practice and from the present gender perspective. There are extreme statements such as the cancellation of the validity of the methods or that there are no facts but interpretations, which require a more sensible balance. We 
believe that a work of grief is imposed regarding the omnipotence of the old epistemic methods, which does not imply the cancellation of its guiding validity, but only an awareness of its limitations. This grief work should not imply a complete break with the past models but a letting go of the non-functional expectations, but also a recovery of what is valuable.

Keywords: $\quad$ contemporary hermeneutics, Luis Garagalza, philological interpretation, grief process of epistemological methods, hermeneutics and genre perspective, antifascism

Recibido: $\quad 8$ de abril de 2019

Aceptado: $\quad 4$ de diciembre de 2019

Nuestros padres destruían alegremente porque vivían en una época que todavía tenía reflejos de la solidez del pasado. Era aquello mismo que destruían lo que prestaba fuerza a la sociedad para que pudieran destruir sin sentir agrietarse el edificio. Nosotros heredamos la destrucción y sus resultados.

Fernando Pessoa, Libro del desasosiego

Vamos a hacer una reflexión sobre la profunda y bien sustentada ponencia de Luis Garagalza: “Tras las huellas de Hermes: la hermenéutica simbólica como contribución a los estudios del imaginario" (Garagalza 2014). Nuestra perspectiva se acercará a la hermenéutica filosófica desde una praxis de la hermeneia poética y una hermeneusis ${ }^{1}$ de textos literarios y artísticos que busca echar mano de los trabajos de los hermeneutas contemporáneos para acercamientos metodológicos que respeten la profundidad de los poetas y su desconfianza de las sistematizaciones demasiado rígidas. También nuestro enfoque estará matizado por una perspectiva de género, particularmente desde la perspectiva latinoamericana, donde las mujeres vivimos sujetas a diferentes formas de violencia de género, algunas muy extremas. Abordaremos también el tema del trabajo de duelo que es necesario realizar respecto de los viejos modelos epistémicos para que los nuevos horizontes que abre la

1 Kerenyi equipara hermeneia con elocutio con verstandlich machen... es un pronunciar, una función ante todo de la lengua, de la glotta, como eficacia de la expresión lingüística. Este término encierra una duplicidad: expresar o comprender un significado. La hermeneusis implica, más bien, un desplegar (Ferraris 2002: 11). 
hermenéutica sean enriquecedores y no otra vez limitantes y dogmáticos. Es decir, que el nuevo paradigma hermenéutico no implique un corte total con el pasado metodológico, una suerte de parricidio filosófico, sino una resignificación de este con una recuperación de lo rescatable en el contexto de una lectura crítica de las limitaciones de los viejos métodos.

Nos centraremos en la primera parte de las tres que integran la ponencia de Garagalza: la que desglosa las repercusiones profundas, revolucionarias diríamos, que trajo consigo la hermenéutica al integrarse a la filosofía. Esta universalización implicó, como lo señaló Maurizio Ferraris (2002), no solo una extensión de prácticas filológicas originalmente localizadas, sino el acceso a "un nivel diferente", el acceso a una reflexión filosófica. ${ }^{2}$

Garagalza analiza de manera contundente en qué consiste este nuevo nivel y los cambios que ello implica, desglosando los ejes que articulan el nuevo paradigma epistémico, al que también podríamos llamar paradigma hermenéutico: 3

- El abandono en la episteme contemporánea de la supremacía del método, como impersonal garante de infalibilidad por el énfasis en las superficies envolventes de las experiencias de sentido que rodean al objeto de conocimiento.

- La conformación del ser humano como un ser hermenéutico, el homo hermeneusis.

- La constitución del mundo y del ser como lenguaje.

- Ruptura de la división entre sujeto y objeto, al priorizarse el tercer horizonte que los engloba. Se trasciende la subjetividad mediante la idea de una fusión de horizontes entre sujeto y objeto. La interpretación, precisamente, sería una fusión de horizontes.

- El lenguaje es más que un órgano de comunicación, es un órgano entre sujeto y objeto, que crea la vinculación. La inseparabilidad de la relación hombre-mundo, sujeto-objeto.

2 "Es la explicitación de estos presupuestos lo que determina la pretensión de universalidad de la hermenéutica contemporánea; una 'hermenéutica filosófica', con base en esto, no significa la interpretación de los textos filosóficos, sino, precisamente, que se impone la interpretación como tarea fundamental de la filosofía" (Ferraris 2002: 12).

3 Según el temperamento de cada quien: los que tienen horror al desorden arbitrario y a la superstición optarán por la episteme; los que aborrecen cualquier forma de dictadura, por una liberalidad hermenéutica. 
- Se cancela también la idea de un referente externo del que el lenguaje sería una representación; este referente se fusiona al lenguaje; el lenguaje es el suceder originario, el lenguaje más que vorstellung, o representación, es darstellung, exposición.

- La sustitución del lugar prioritario otorgado al lugar del sujeto por la pregunta sobre la interpretación.

- La existencia de un sustrato simbólico sobre el que se construye la posibilidad del lenguaje.

De entrada, consideramos que hay un componente profundamente civilizatorio en la propuesta de este paradigma hermenéutico, pues al privilegiar el lenguaje y el símbolo sobre el viejo imperio de la razón, abre espacios de hermandad entre diversas culturas. Habría en este paradigma una posibilidad de fraternidad entre seres humanos y culturas diversas, análoga a lo que tejió el neoplatonismo florentino en el siglo xv. Fue este viejo paradigma el que celebró la universalidad de lo humano bajo distintos climas y tiempos, y exaltó la más alta herencia humana: el acceso a la dimensión espiritual. Esta reciente valoración de lo simbólico también permite un rescate de la totalidad de las dimensiones que alberga lo privilegiado que puede llegar a ser el ser humano.

Nos gustaría llevar estas reflexiones filosóficas de regreso tanto a la práctica filológica en la literatura, como al estar en el mundo como mujer latinoamericana. En esta última circunstancia, la de una mexicana enfrentada a una sociedad que impone la violencia a las mujeres, tanto física como emocionalmente, así como la que se genera desde la desigualdad y la emanada de los aceptados estereotipos de género, tenemos que decir que es difícil eludir la facticidad de la violencia. Estos son hechos interpretables sí, pero que desde su facticidad inciden con brutalidad, y no puede disolverse su impacto borrándolos en el discurso. Si al interpretarlos su facticidad se disuelve en ficción interpretativa, corremos el riesgo de volvernos cómplices perversos de su perpetuación. De pronto la realidad vivencial impone límites a la afirmación nietzschiana de que no existen los hechos sino solo interpretaciones (Nietzsche 1980: 315). Es muy importante no hacer un silogismo universal de una afirmación solo válida para cierta dimensión abstracta del pensamiento.

Como señalamos, esta propuesta filosófica, por su valoración del sustrato simbólico que subyace al fenómeno del lenguaje, tiene una apertura al 
otro profundamente civilizatoria. Pero, en México, asistimos al surgimiento social de un fenómeno paralelo y contrario, una serie de daños que desafían cualquier interpretación. Asistimos en nuestro país al ascenso de la violencia pura, perpetrada por el crimen organizado. Es una violencia que escapa a las viejas interpretaciones sociológicas o psicológicas remitiéndonos al fenómeno del mal puro; es el mal puro en su absurda facticidad escupiéndole a la cara a cualquier intento humano de explicación, desafiando cualquier hermenéutica, quedando en los márgenes de cualquier esfuerzo de humanización, produciendo de hecho márgenes indomables. Señalamos este hecho -que nos parece un fenómeno paralelo al nuevo paradigma, quizá olvidado por este-, de cómo los centros sociales tienden a silenciar las periferias.

Interpelando al olvido, por las teorías, de las condiciones concretas de la existencia, Emmanuel Lévinas lanza su exigencia de un pensamiento aterrizado en el cuerpo y su contingencia 4 y amonesta sobre el brutal peligro de engaño y deslealtad que implica todo abandono teórico de esta consideración: "toda estructura social que anuncie una liberación respecto al cuerpo y que no lo compromete se vuelve sospechosa como una deslealtad, una traición. Las formas de la sociedad moderna, fundadas sobre el acuerdo de voluntades libres, no parecerán solo frágiles e inconsistentes, sino falsas y mentirosas" (Lévinas 2002: 17).

Pero, regresando a nuestro nuevo paradigma, creemos que podríamos acercarnos a esta hermenéutica que accede al estatuto filosófico como un trabajo compensatorio ante las deficiencias de las viejas epistemologías univocistas. Esta hermenéutica filosófica es en cierto modo como un trabajo de duelo ante los desastrosos subproductos de las grandes utopías intelectuales del siglo xx. No hubo socialismo real, por ejemplo; solo socialismos burocráticos que fueron adquiriendo rostros aberrantes (Kozik 1972).

De vuelta al trabajo de duelo, en el que, si se hace correctamente, habría que pasar por varias etapas: 1) la asunción de pérdidas; 2) la recuperación parcial, en otro espacio, de aspectos valiosos o necesarios de lo perdido; 3) el descubrimiento de ganancias imprevistas; 4) el caminar con mucho esfuerzo hacia un horizonte de nuevas promesas. Un trabajo de duelo bien

4 Lévinas señala: "La esencia del hombre no está en la libertad, sino en una especie de encadenamiento. [...] Ser verdaderamente uno mismo no es echar a volar de nuevo por encima de las contingencias, extrañas siempre a la libertad del yo; es, al contrario, tomar conciencia del encadenamiento original ineluctable, único, a nuestro cuerpo; es sobre todo, aceptar este encadenamiento" (Lévinas 2002: 17). 
hecho implica, desde el punto de vista del psicoanálisis freudiano, una difícil pero posible recuperación del lugar del sujeto. El sujeto, tras de un proceso que puede ser muy doloroso, queda liberado y, de alguna manera, enriquecido por la experiencia. 5 Por el contrario, en el caso de la melancolía, como forma patológica de abordar una pérdida, lo que se produciría sería la autodestrucción del propio sujeto. ${ }^{6}$ Esta diferencia entre el duelo y la melancolía, creemos, puede aplicarse a la nueva hermenéutica filosófica y su relación con los viejos modelos epistemológicos. En el caso del duelo, habría una pérdida de la fantasía de la omnipotencia epistémica de estos, pero, al mismo tiempo, una recuperación saludable del lugar del sujeto de conocimiento. En el caso de una postura melancólica ante el derrumbe de las viejas idealizaciones epistémicas, lo que se daría sería también un derrumbe muy peligroso del lugar del sujeto de conocimiento. El sujeto epistémico ante el derrumbe del modelo omnipotente también se destruiría melancólicamente a sí mismo.

5 “Mas, ¿en qué consiste la labor que el duelo lleva a cabo? A mi juicio, podemos describirla en la forma siguiente: el examen de la realidad ha mostrado que el objeto amado no existe ya y demanda que la libido abandone todas sus ligaduras con el mismo. Contra esta demanda surge una oposición naturalísima, pues sabemos que el hombre no abandona gustoso ninguna de las posiciones de su libido, aun cuando les haya encontrado ya una sustitución. Esta oposición puede ser tan intensa que surjan el apartamiento de la realidad y la conservación del objeto por medio de una psicosis desiderativa alucinatoria. Lo normal es que el respeto a la realidad obtenga la victoria. Pero su mandato no puede ser llevado a cabo inmediatamente y solo es realizado de un modo paulatino, con gran gasto de tiempo y de energía de cara, continuando mientras tanto la existencia psíquica del objeto perdido... No nos es fácil indicar en términos de la economía por qué la transacción que supone esta lenta y paulatina realización del mandato de la realidad ha de ser tan dolorosa... Al final de la labor del duelo vuelve a quedar el yo libre y exento de toda inhibición" (Freud 1917: 2092).

6 "Apliquemos ahora a la melancolía lo que del duelo hemos averiguado. En una serie de casos constituye también evidentemente una reacción a la pérdida de un objeto amado. Otras veces, cuando las causas estimulantes son diferentes, observamos que la pérdida es de naturaleza más ideal. El sujeto no ha muerto, pero ha quedado perdido, como objeto erótico (el caso de la novia abandonada); pero no conseguimos distinguir claramente qué es lo que el sujeto ha perdido y hemos de admitir que tampoco a este le es posible percibirlo conscientemente. A este caso podría reducir también aquel en el que la pérdida causa de la melancolía, es conocida al enfermo, el cual sabe a quién ha perdido, pero no lo que con él ha perdido. De este modo nos veríamos impulsados a relacionar la melancolía con una pérdida de objeto sustraída a la conciencia, diferenciándose así del duelo en el cual nada de lo que respecta a la pérdida es inconsciente" (Freud 1917: 2092). 
La ganancia de este trabajo hermenéutico filosófico, hecho como duelo saludable, sería la obtención de una conciencia más amplia, donde ya no será la "omnipotencia racional" la que imponga su autoridad absoluta sino una conciencia consciente de sus propias limitaciones, una conciencia con raíces existenciales y humanas. Esta no debe desembocar en un relativismo sofístico o retórico, sino en el acatamiento del propio principio de realidad, con una comprensión de nuestros condicionamientos y fronteras. Es una conciencia consciente, por decirlo así, de nuestra contingencia histórica constitutiva; más prudente, pero también, necesariamente, más amplia e incluyente. Es una conciencia que, en lo epistémico, toma en cuenta los alcances, necesariamente acotados, de cualquier punto de vista histórico, al aludir a lo limitado de nuestro "fundamento" interpretativo en términos de Pierce. ${ }^{7}$

Pero existe el peligro de que se adopten los postulados de la hermenéutica filosófica con superficialidad, cayendo, creo, en la arbitrariedad y la exaltación de un espontaneísmo interpretativo, desembocante en un excesivo multivocismo, en una desenfrenada apertura interpretativa que haga caso omiso de los elementos correctores de toda interpretación. Abrir la interpretación a un exceso de arbitrariedad y libertad acabaría siendo como tirar al niño junto con el agua sucia, donde se pierden referentes importantes aportados por los viejos métodos para el sujeto cognitivo. Entonces acabaríamos ubicándonos no en una plataforma de posibles prudentes ganancias sino en un derrotero hacia más pérdidas y desorientación. En ese momento entraríamos en el espacio de la melancolía con su autodestrucción, no en el del trabajo del duelo.

Tanto en la filología como en la vida cotidiana el espontaneísmo interpretativo acaba siendo, por su arbitrariedad, un acto de imposición y de violencia contra el lugar del otro, paralelo, aunque aparentemente inverso, al del univocismo patriarcal y autoritario del sujeto epistémico absoluto. Sucede que el desordenado padre tribal ${ }^{8}$ y el rígido padre fascista acaban por parecerse,

7 Al final de la mencionada obra Pierce acaba identificando el fundamento con una noción semántica mucho más familiar: la connotación. Se trata de "la referencia del símbolo a su fundamento, a través de su objeto, esto es, su referencia a los caracteres comunes de sus objetos, o, lo que es lo mismo, su connotación" (CP 1.559). Nuevamente esta noción sugiere la estrecha conexión que se puede establecer entre sentido, significado e interpretante (Uxía Rivas 2019).

8 Nos referimos al padre que se vive a sí mismo como la ley, que no está sujeto a ninguna restricción externa, que se apodera de todas las hembras y expulsa a los otros varones, en el modelo del padre de la hora primitiva que Freud delinea al hacer su 
al vivirse a sí mismos como la ley encarnada, en vez de sujetarse a esta, en vez de remitirse a un espacio tercero - el de los consensos legales- garante de una convivencia respetuosa con los otros. Ni el arbitrario padre tribal ni el militarizado padre fascista salen de su egocentrismo para sujetarse a esa dimensión "otra" de configuración de lo social, conformada por una red de acuerdos sensatos y respetuosos para el bienestar común. Lo mismo ocurre en la filología: nada más aburrido ni banal que una interpretación personal y autista, que no atiende a contextos ni a orden ni a métodos ni al trabajo de otros investigadores. Poco aportará una interpretación de este tipo.

En esta limitación que nos es constitutiva, el contacto con la verdad no puede limitarse a ser solo interpretación arbitraria. Aquí habría que agregar que, así como en Lacan hay un otro con minúsculas y un Otro con mayúsculas, 9 también se podría hablar, para los que trabajamos con la cultura y la historia, de una "verdad" con minúscula (una verdad sujeta a restricciones históricas y metodológicas) pero que sigue siendo orientadora de la conciencia. Esta verdad con minúsculas se opondría a una "Verdad", con mayúsculas, como espacio ontológico absoluto. Esta última es inaccesible para los métodos epistémicos sociales y filológicos; pero tratar de realizar un

reconstrucción de los orígenes de la sociedad humana: “...los hombres vivieron primitivamente en pequeñas sociedades, teniendo generalmente cada uno una sola mujer, y a veces, si poseía un alto grado de poderío, varias, que defendía celosamente contra todos los demás hombres. Asimismo pudo no ser el hombre un animal social y vivir, sin embargo, como el gorila, con varias mujeres de su exclusiva pertenencia. En los grupos de estos animales se ha comprobado siempre, efectivamente, la presencia de un único macho adulto. Cuando el gorila joven llega a un cierto estadio de su crecimiento, lucha con los demás por el dominio absoluto del grupo, y después de matarlos o expulsarlos se constituye en jefe supremo. Los jóvenes machos así eliminados y errantes de lugar en lugar, considerarán a su vez, como un deber, cuando lleguen a conquistar una hembra, impedir las uniones consanguíneas demasiado íntimas entre los miembros de una misma familia" (Freud 1913: 1827-1828).

9 "Sabemos que según Lacan el sujeto, es el sujeto del deseo, que es la esencia del hombre. Este sujeto una vez entrado en el lenguaje, quedará dividido y marcado por la ineliminable carencia de un objeto perdido, un vacío que muy a menudo intenta llenar y tapar de modo patético o patológico. Originalmente escindido está, como 'efecto del lenguaje', responsable por su separación y alienación. Para que haya deseo postula una condición de posibilidad que es la Cosa, como el primero exterior, es aquello en torno a lo cual se organiza todo el andar del sujeto, Cosa en tanto en que Otro absoluto del sujeto, es lo que se trata de volver a encontrar. La Cosa es el 'fuera de significado' y en función de ese fuera de significado y de una relación patética con él, el sujeto conserva su distancia y se constituye en un modo de relación, de afecto primario, anterior a toda represión" (Hoezen 2002: 2-3). 
acercamiento a "la verdad" con minúsculas, en su estatus, más ético y vivencial que ontológico; es orientador e ineludible: es esta una verdad paulatinamente construida, mediante una praxis ética, responsable y honesta. Es una verdad que se iría construyendo a través de la experiencia en el camino y de la herencia de otras experiencias. El sentido de esta "verdad" con minúsculas es lo que acaba dándole sentido al discurso mismo y hay que pensarla dentro de un proceso continuo de construcción análogo al concepto de "formación” en Gadamer. ${ }^{10}$

Respecto de la interpretación en relación con la verdad con minúsculas, a este Norte del discurso y la conciencia que es la "verdad" con minúsculas, habría que agregar que hay muchos tipos de interpretaciones: las hay elaboradas con gran conocimiento de causa y las hay surgidas desde la ignorancia y los prejuicios; las hay maduras y las hay inmaduras. Las interpretaciones siempre evolucionan, junto con los que las elaboramos. Porque vivimos sujetos a la particular perspectiva de un espacio y un tiempo determinados, ${ }^{11}$ nuestras interpretaciones están condenadas a transformarse, a quedar siempre abiertas, a completarse, a prometer volverse más justas.

El acercamiento a la "verdad" con minúsculas, el acercamiento a la comprensión de "lo dado" no tiene que sustituirse por una diáspora de interpretaciones, sino por una sabia evolución hacia una mayor integración y comprensión. En este nuevo horizonte, en que se perfila como prioritaria la interpretación, no puede ser absoluta la pérdida del método, pues los métodos de alguna manera sintetizan valiosos conglomerados de experiencia. El método no puede sustituir totalmente al sujeto de conocimiento, como lo pretendieron hacer los discursos hegemónicos del marxismo y del psicoaná-

10 El término alemán Bildung, que traducimos como formación, significa también la cultura que posee el individuo como resultado de su formación en los contenidos de la tradición de su entorno. Bildung es, pues, tanto el proceso por el que se adquiere cultura, como esta cultura misma en cuanto patrimonio personal del hombre culto. No traducimos dicho término como cultura porque la palabra española significa también la cultura como conjunto de realizaciones objetivas de una civilización, al margen de la personalidad del individuo culto, y esta suprasubjetividad es totalmente ajena al concepto de Bildung, que está estrechamente vinculado a las ideas de enseñanza, aprendizaje y competencia personal (Gadamer 2007: 38).

11 "La formación pasa a ser algo estrechamente vinculado al concepto de la cultura, y designa en primer lugar el modo específicamente humano de dar forma a las disposiciones y capacidades naturales del hombre. Entre Kant y Hegel se lleva a término esta acuñación herderiana de nuestro concepto" (Gadamer 2007: 39). 
lisis en el siglo $\mathrm{xx}$, pero sigue siendo una herramienta incuestionablemente útil, con su muy valiosa herencia de saberes.

De las posturas de la hermenéutica filosófica, en mi ramo, creo que las más productivas se acercan a la propuesta de Cassirer, quien propuso una interacción entre los tres diferentes modos simbólicos: el lingüístico, el mitopoético y el teórico crítico o metódico. Cassirer no se deshace del método, sino que lo abre, lo pone a dialogar, y ello a mi juicio resulta muy productivo. ${ }^{12}$

En este sentido, la situación de la crítica filológica contemporánea no se distanciaría de lo que ocurrió en la física del siglo xx. El cuestionamiento del posicionamiento objetivo absoluto surgió dentro de la misma física con hallazgos como los del principio de incertidumbre de Heisenberg o los de la teoría del comportamiento dual de la luz. Ambos confrontaron la impersonalidad del viejo logos puro e indoblegable. La captura del universo físico por el método científico, que en siglos anteriores se consideraba definitivamente objetiva, ahora se ve obligada a admitir en su seno a la incómoda subjetividad. Ahora hasta la ciencia se ve obligada a invitar al sujeto. El método tenía que incorporar la basculación de la interpretación, pero ello tampoco invalidaba las ganancias obtenidas mediante la antigua estructura metodológica;

12 "La antropología filosófica de Cassirer aun sin abandonar los presupuestos kantianos, los considera excesivamente racionalistas y ve necesario ampliar el planteamiento crítico más allá del ámbito del conocimiento científico, porque la ciencia no es el único medio a través del que el hombre configura la realidad. La ciencia ofrece una comprensión del mundo cuya característica principal consiste en la inserción de lo particular en una forma universal que ordena la realidad mostrando cómo cada individuo es un caso concreto de una ley general. Pero además de la ciencia, hay otras formas de configuración del mundo humano que no son 'científicas', sino que pertenecen al ámbito prerracional e imaginativo como, por ejemplo, el lenguaje, el arte, o el mito" [Cassirer 1972, 1: 20]. Así, señala: "En lugar de investigar meramente los presupuestos generales del conocimiento científico del mundo, había que proceder a delimitar con precisión las diversas formas fundamentales de 'comprensión' del mundo y a aprehender con la mayor penetración posible cada una de ellas en su tendencia y forma espiritual peculiares" [Cassirer 1972, 1: 7]. "Sin embargo, el objetivo último del estudio de la cultura no era el conocimiento de las creaciones culturales por sí mismas, sino llegar a comprender mejor al ser humano al analizar la estructura y especificidad de sus obras. Cassirer corrigió, ampliándola, la definición aristotélica clásica del ser humano como el 'animal racional', por considerar que toma la parte por el todo, pues el modo como el hombre configura el mundo no es siempre de índole racional. Si bien todas las formalizaciones humanas 'objetivan' las impresiones recibidas - es decir, constituyen sus propios objetos-, no todas ellas 'conceptualizan'. Por ejemplo, en el mito se lleva a cabo una objetivación imaginativa, en el arte una objetivación intuitiva o contemplativa, y solo en el lenguaje y en la ciencia se produce una objetivación conceptual" [Cassirer 1979: 187] (Amilburu 2010). 
simplemente implicaba el poder sostenerse en un pie o en el otro, como ocurre con la danza.

De manera análoga dentro del campo literario tiende a producirse una alternancia bípeda entre modelos explicativos, un balanceo entre interpretaciones complementarias, que generan espacios de dialogicidad, muchas veces afortunados. En el caso de la poesía, Patxi Lanceros buscará, por ejemplo, realizar un entrecruzamiento de dos perspectivas, articulando un enfoque histórico materialista con uno simbólico-sagrado. Para Patxi Lanceros no habría mímesis sin símbolo, pero tampoco puede existir símbolo sin carne histórica. ${ }^{13}$ ¿No ocurrirá acaso lo mismo, en otros campos de la interpretación, donde no habría mímesis sin símbolo, pero tampoco símbolo sin mímesis de lo históricamente dado?

Quizá el duelo definitivo para este nuevo paradigma filosófico sea el de la despedida al monólogo absoluto del método, de ese método cerrado en un autismo que deja de mirar la especificidad y riqueza del objeto. Sobraron los casos de interpretaciones de textos o cuadros que usaron al arte para demostrar la efectividad e infalibilidad del método, presumiendo su musculosa maquinaria, casi silogística, y dejando de lado facetas de realidad, fundamentales al objeto estudiado, destruyendo con ello su especificidad.

Creo que, al menos en la crítica literaria, viene imperando, gracias al nuevo paradigma hermenéutico, una prioridad del objeto estudiado por sobre cualquier método apriorístico. El método dejó de ser plataforma impersonal, cuasi divina, del saber, mostrando los émbolos racionales de sus arrogantes músculos de superhéroe epistémico, a la vez que abandonado al objeto femenino en lo inerte. Eran metodologías que acababan leyéndose únicamente a sí mismas, y termina sucediéndoles lo que al "cociente revisionista" del clinamen, según Harold Bloom, en el que incurren muchos poetas poderosos, quienes nunca leen verdaderamente a su predecesor; solo se leen a sí mismos. ${ }^{14}$ Así, los grandes métodos hegemónicos también incurrían en un

13 "La obra de Hölderlin — tensional más que dialéctica - atribuye a la poesía (al arte en general) un espacio fundamental y propio: el arte no se trivializa en mera reproducción de las cosas (Platón), ni se somete a ser mera imitación de la idea (Plotino). Llena el ámbito que media entre lo histórico y lo trascendental, entre lo moderno y lo eterno, sin adherirse dogmáticamente a ninguno de los extremos sino dejando ser en la tensión" (Lanceros 2006: 370).

14 Clinamen es para Harold Bloom uno de los cocientes revisionistas que consiste en la mala o deficiente lectura hecha por el poeta hijo del poeta padre. "Los poetas, cuando ya se han vuelto fuertes, no leen la poesía de $\mathrm{X}$, ya que los poetas verdadera- 
clinamen o negligente interpretación, pues nunca atendían cuidadosamente a su femenino objeto abandonado. En general dentro de una cultura patriarcal, hay un clinamen preestablecido respecto a cualquier posición femenina pasiva, una lectura arrogantemente negligente, donde el desplante patriarcal acaba por solo leerse a sí mismo.

El camino es superar el clinamen metodológico, creo, y procurar una mucho más cuidadosa lectura de los textos por sobre los prejuicios o presupuestos metodológicos. En este nuevo paradigma los textos resultan los puntos de partida y nos obligan como sujetos a viajar hacia su propio lugar. El objeto artístico o literario tiende a exigir, como ocurre en un verdadero encuentro amoroso, que nos desplacemos hacia ellos. El objeto artístico gravita, de hecho, tan poderosamente en sí mismo, que puede llegar a sobrevivir a la historia, y, también, no a uno sino a varios enfoques. El texto, el amor y la comprensión nos exigen necesariamente un cambiarnos de lugar, un acercarnos al otro; nos modifican como sujetos. Gadamer en un momento declara: "reconocer en el extraño lo propio y hacerlo familiar es el movimiento fundamental del espíritu, cuyo ser no es sino retorno a sí mismo desde el ser otro" (Gadamer 2007: 43). Pero antes, creemos, habría que hacer un camino de desplazamiento de lo propio al aproximarnos al otro, para que pueda darse después este enriquecedor camino de retorno hacia el propio centro espiritual, sin que este retorno sea autista, sea un negligente clinamen más. Este retorno tenemos que pensarlo no encerrado en un silogismo egótico, sino involucrando antes la propia movilidad amorosa, mediante una apertura de bondad y hospitalidad, cercano a la propuesta de Lévinas, ${ }^{15}$ donde tendríamos que desplazarnos de nuestras zonas de confort y de identidad para lograr un verdadero encuentro con el otro; para que a su vez esta develación del otro pueda llevarnos a una profundización y ampliación de las posibilidades de lo propio. Este desplazamiento hacia el otro también destapará lo que podríamos estar desconociendo de nosotros mismos.

mente fuertes solo se leen a sí mismos. Para ellos, ser sensato equivale a ser débil, y comparar, de manera exacta y justa, equivale a no ser uno de los elegidos" (Bloom 1977: 29).

15 "La revelación del otro que plantea Lévinas es una radical inversión de la intencionalidad del conocimiento objetivo. Esto implica que la primacía la tiene la afectación corporal y sensible provocada por lo extraño o exterior a sí, lo otro que irrumpe, y la consecuente constitución de la subjetividad desde afuera y a partir de la irrupción del Otro" (Palacio 2013: 7). 
Somos invitados actualmente también a un asedio a los textos, desde diversos enfoques metodológicos, mediante metodologías no univocistas sino dialogantes, ya no arrogantes sino profundamente atentas y sensibles a su objeto, metodologías no exclusivistas sino incluyentes de otras perspectivas. Las metodologías filológicas, actualmente tienden a la askesis, ${ }^{16}$ ese otro "cociente revisionista" que implica el vaciamiento del sí mismo, en la asunción de una máxima prudencia y atención al otro. No sé si valdría hablar aquí de métodos abiertos que poseen piel sensible o si de interpretaciones perfeccionables que parten de una estructuración metodológica. Habría un encuentro entre lo que podrían ser metodologías blandas y táctiles respecto a su objeto y por otro interpretaciones autocríticas y rigurosas, que buscan mayor integración y coherencia, mayor justeza, condensando una mayor reflexión. Se impondrá una phronesis tanto respecto al autismo patriarcal y algo impositivo de las metodologías, así como también una phronesis respecto a ese otro autismo espontaneísta, y romántico, excesivamente emocional y acrítico.

Podría aquí también hacerse extensivo el giro hermenéutico que hace Lévinas del lenguaje como responsabilidad ética, ${ }^{17}$ hacia la episteme. Ello implicaría, no una imposición de un hermético modelo preestablecido, sino una apuesta por un acercamiento sensible y atento a las peculiaridades del otro, sea este un texto u otro sujeto. La relación ética que vincula al lenguaje con la bondad según Lévinas, y que nos obliga a "responder del Otro y por el Otro", nos señala Marta Palacio, que es "una relación que permite a un ser separado entrar en relación con otro sin anularlo" (Palacio 2013: 7). Este compromiso de respeto y de no anulación del otro, desde lo propio, creo, debería hacerse extensiva a todo modelo epistémico.

16 "La sublimación poética es una ascesis, una purgación que tiene por meta más cercana un estado de soledad. Embriagado por la nueva fuerza represiva de un Contra-Sublime personalizado, el poeta fuerte, en su demoniaca elevación, es autorizado para que vuelva su energía contra sí mismos, y logra, a un precio terrible su más definida victoria en la lucha con los poderosos muertos" (Bloom 1977: 134).

17 "Plantear el ser como Deseo y como bondad... es afirmar que sostenerse desde el interior - producirse como yo- es sostenerse por el mismo gesto que se vuelve ya hacia el exterior para extraverter y manifestar — para responder por lo que toma-, para expresar: que la esencia del lenguaje es bondad, o aun, que la esencia del lenguaje es amistad y hospitalidad" (Lévinas 2012: 345). 


\section{La pérdida}

Quizá habría que puntualizar que la pérdida definitiva no es la del método, en el nuevo paradigma, no es que el método, por su rigidez y limitaciones, venga a ser sustituido por el amplio espacio amorfo de interpretaciones, sino que el camino es el de ir logrando interpretaciones más sólidas a la vez que sensibles, capacitadas para obtener consensos, para conquistar mayor validez. El método, al menos en la crítica literaria, sigue sosteniendo en este proceso una validez, limitada sí, parcial también, pero necesaria aunque sea solo como atención autocorrectiva de la interpretación. La utilización del método por la interpretación ya no es una garantía, pero sí un principio, no una gigantesca carretera de certezas "científicas" pero sí un sendero, aunque acotado, por su orden, extremadamente útil.

Respecto de la crítica literaria, resulta que los mayores aciertos tienden a darse a través de una secuencia de interpretaciones con enfoques más amplios y dialécticos. Las interpretaciones nunca nacen siendo definitivas, sino que van abriéndose a miradas complementarias, van abriéndose al diálogo y a la autocorrección, para ir alcanzando mayor precisión a la vez que más coherencia.

La disciplina del método aporta rigor a la interpretación, y la interpretación, con una sensibilidad vitalista, abre al método miradas mucho más sensibles y completas.

Actualmente no habría tanto una cancelación de la validez del método ni de las "verdades" obtenidas mediante los métodos, al menos en la crítica literaria, sino una puesta en contexto, una mise en drame, de métodos alternativos en un diálogo tensionado por diversos enfoques. También habría el surgimiento de nuevos métodos, desde el "cociente revisionista" de la apófrades o "resurrección de los muertos", en los términos de Harold Bloom. Es el caso del ejemplar análisis que hace Patxi Lanceros tanto de Hölderlin como de Baudelaire para hablar de la dialéctica entre la mimesis y la poiesis que se debe dar en la poesía y que está presente en ambos autores. Ese diálogo, entre la dimensión de lo histórico y la de lo sagrado, como la que defienden ambos autores, puede dar muy buenos resultados, en mi experiencia (Lanceros 2006: 363-370).

Heidegger renunció a la fundamentación de una metodología garante de verdad, sí, pero la pérdida aquí, creo, está en la seguridad absoluta de las plataformas garantes de verdad, como deus ex machina del saber, como lu- 
gares únicos de acceso confiable a este. Sin embargo, las metodologías también han otorgado marcos de orientación política y moral imprescindibles, para una pertinente lectura ideológica, o para la asunción de principios de realidad ineludibles sin los cuales podemos perdernos trágicamente y equivocarnos para la acción, como le ocurrió al mismo Heidegger con su falta de perspectiva crítica frente al fascismo. No tendremos además que ir tan lejos para encontrar ejemplos, pues abundan estos en nuestro México tan cercano y violento, donde puede pagarse con el precio del horror cualquier desatención a la facticidad, donde ser demasiado "inocentes" es convertirse en "idiotas", como decía un gran maestro sabio.

\section{Horizonte de promesas}

Uno de los horizontes más atractivos para este nuevo paradigma hermenéutico es el de la viabilidad de una salida posible al impass de la dialéctica ilustrada, que denunciaron Theodor W. Adorno y Max Horkheimer, a ese modelo "objetivista" orientado exclusivamente por la búsqueda de la eficacia en el dominio de seres y cosas. Fue un modelo que no desembocó en el progreso, como lo prometía, sino en formas cada vez más sistematizadas, y aberrantes, por sofisticadas, de barbarie. Fue un modelo epistémico que en su forma más purificada derivó en fascismo.

A este lo caracteriza una tajante división entre sujeto y objeto, por lo que la disolución de esta división que abre el nuevo paradigma hermenéutico vislumbra un espacio de esperanza. Sin embargo, respuestas exclusivamente vitalistas o ingenuas y poco advertidas de los juegos de poder que configuran las relaciones sociales pueden llevar a peligrosos desenlaces, en una sociedad conformada por enclaves de dominación, que nada tienen de ingenuos y sí de sistemáticamente criminales, donde una infantil distracción se paga hasta con la muerte. Estos brutales juegos de poder y perversión están elegantemente revestidos por interpretaciones que, desde los balcones del prestigio social, con flagrante falsedad niegan la realidad de hechos que con dolor, sangre y hasta muerte hablan. Se evita, de hecho, a toda costa su escucha en las redes auriculares del estatus y la comodidad social. Peligramos si no tomamos en cuenta la verdad, y nos fugamos en un cómodo mundo de autoficción interpretativa, y aquí no hablo de la Verdad metafísica con mayúscula, sino de verdades cotidianas, sociales, políticas, de enseñanzas históricas, personales, 
familiares. Si no aprendemos a observarlas y reconocerlas estaremos condenados a repetirlas. Lo no simbolizado regresa en lo real, nos advierte Lacan, y regresa y regresa y regresa hasta que por fin lo advertimos y nos transformamos, o este nos destruye. Peligra, y mucho, un país o una persona que no se asoma a aprender de su propia historia; peligra una mujer, por ejemplo, aun en los medios académicos ilustrados, que no tome en cuenta los feminicidios y las situaciones de violencia de género que tanto abundan en México.

Las gadamerianas fusiones de horizontes entre sujetos y objetos deben darse, pero sin olvidarse, creo, de las advertencias de estos ineludibles hitos de realidad.

\section{Nueva recuperación del sujeto}

En cuanto a la sustitución del lugar prioritario otorgado al sujeto por la pregunta sobre la interpretación, creo, es un viejo problema del siglo xx que involucra la cuestión de la libertad y de la responsabilidad. Tanto el psicoanálisis como el marxismo cuestionaron la supuesta libertad del sujeto al exponer los determinismos psíquicos y sociales que lo arman. A estos dos saberes hegemónicos, respondió el existencialismo postulando el lugar del sujeto como un lugar "otro", distinto al de la determinación, un lugar de libertad, como el lugar mismo de la libertad. André Breton lanzó un verso extraordinario y categórico: "libertad color de hombre". La libertad no existe en las determinaciones, pero a esta la sustenta siempre la esencia del hombre. Ello también lo señalaron desde el Renacimiento Picco della Mirandola y Fernán Pérez de Oliva.

Actualmente, a través de trabajos de hermenéutica epistémica como Las palabras y las cosas de Foucault, y Eros y magia en el Renacimiento, de Ioan Culianu, resulta fundamental preguntarnos por los horizontes de interpretación que conforman el lugar desde donde se plantea el sujeto del conocimiento. Pero aun con todas las nuevas determinaciones que llega a develarnos la hermenéutica epistémica, creo que la pregunta sobre el sujeto no puede disolverse completamente. Se volverá insurgente siempre que estamos frente al dilema de una problemática moral o de una defensa de la dignidad humana ante condiciones de avasallamiento. La libertad no es absoluta, en el sentido de que no es indeterminada (no hay Libertad con mayúsculas); nunca estaremos libres de condicionamientos materiales, psíquicos, sociales y hasta hermenéuticos, pero siempre exigirá la libertad su lugar con minúsculas, que 
es el propio lugar del sujeto humano; esta libertad del sujeto de la conciencia aparecerá a pesar de las constricciones y cárceles físicas o mentales; aparecerá, aunque solo sea como posibilidad o como conciencia. Su lugar es el de la misma dignidad humana. Sobrevivirá aún, simplemente en el acto de repudio moral de la conciencia, ante aquello que busca destruirnos.

La libertad exigirá su lugar humano precisamente a través de la conciencia; a través de esa conciencia que nos abre a un saber surgido de nuestra propia praxis vivencial o al producido por las diferentes disciplinas epistémicas. La libertad incidirá como la posibilidad de una mejor opción, esta vez no ciega sino consciente; repuntará en una decisión que puede hacerse, esta nueva vez, de manera responsable; o respirará también simplemente como silenciosa, paciente resistencia; o será acunada como alternativa moral, ante la injusticia y el dolor, por la conciencia aún en condiciones de impotencia. Es aquí donde incide, por necesidad, la cuestión del sujeto. El sujeto del nuevo paradigma hermenéutico no es el sujeto romántico, centrado en su propia impulsividad; es un sujeto descentrado, señala Garagalza. Es un sujeto al que también podríamos pensarlo desplazándose de su zona de confort para ir a comprender al otro, en sus condiciones físicas de dificultad y precariedad, como lo señalaría Lévinas. Yo diría que el sujeto contemporáneo se encuentra siempre transformándose; es un sujeto dinamizado por los procesos de conciencia; y aunque este sea receptor de las redes de símbolos, se mantendrá siempre activo e insurgente en un irse transformando a través de una relación creativa y propositiva con estas, en un adquirir mayor conciencia al profundizar en estos mismos símbolos, y en su poder de posicionarse a través de una nunca abandonada decidida autoría de sí mismo. La conciencia se encuentra siempre en expansión y ello provee el horizonte de una promesa de mayor libertad.

Quizá para este nuevo sujeto podría iluminarnos el ejemplo de los poetas modernos, el poeta moderno aunque abandona la fe en el yo lírico del poeta romántico, en ese sujeto solo centrado en sí, tiene, para volverse moderno, que salir de sí mismo y entrar en diálogo con los discursos críticos de su tiempo; tiene que dejarse afectar por estos, dejarse hasta seducir un poco por ellos; incluso tiene que dejarse "demonizar"; no pierde, sin embargo su propio lugar, pues este se encuentra sustentado por su propia tradición, la tradición crítica misma de la poesía. ${ }^{18}$ La original adhesión del poeta moderno

18 "La poesía romántica es revolucionaria no con, sino frente a las revoluciones del siglo; y su religiosidad es una transgresión de las religiones” (Paz 1974: 78). 
al pensamiento crítico teórico termina en desencanto. Una serie de amoríos y divorcios, de adhesiones y de apostasías, ocurren entre el poeta moderno y la tradición crítica occidental, nos señala Octavio Paz. ${ }^{19}$ Pero este finalmente nunca pierde el soporte de la conciencia de su propia historia y de su propia tradición al enfrentar su modernidad histórica; no pierde su lugar de sujeto en este diálogo contra un poderoso contrincante que mediante su hegemonía amenaza con desposeer cualquier frágil voz independiente. El poeta estará siempre defendiendo y replanteando su lugar, su libertad poética, su lucidez, su creatividad, su "sujetidad", entendida esta como sujeción a las condiciones de lo real y a lo simbólico, sí, pero a la vez como subjetividad creativa, vital y beligerante. La poesía mantiene siempre vivo el lugar del sujeto vivo, valga la redundancia, respecto a condicionamientos históricos distintos, debido a su pujante creatividad.

No será el próximo sujeto un ente deshilvanado por interpretaciones que va a la deriva de este o aquel estímulo interpretativo, obediente de cualquier capricho ajeno: no es así el que podría sustituir al viejo sujeto en este nuevo paradigma. Necesitaremos más que nunca a ese sujeto, que, como señalaba Hannah Arendt, frente a los sistemas totalitarios (que inclinan a la obediencia y a la lobotomización moral), se detiene a pensar, que se detiene, contra la corriente, a orientarse hacia un posible horizonte éticamente óptimo. Y aquí también surge la necesidad de los valores que es importante que aborde el nuevo paradigma para no sumergir al hombre dentro de un relativismo neutralizante y desorientador, sino para impulsarlo mediante vivificantes nuevas tomas de conciencia hacia la defensa de una mayor integridad humana en todos los sentidos. Es de esta manera que visualizaríamos un saludable proceso de duelo respecto de la pérdida de los viejos métodos hegemónicos del saber, no como una pérdida de la dirección de los caminos, sino como una restricción más realista de nuestras expectativas en estos.

\section{Bibliografía}

Agustín, san (2013). Obras completas. Confesiones, vol. VII. Madrid, Biblioteca de Autores Cristianos.

19 "La historia de la poesía moderna - al menos la mitad de esa historia- es la de la fascinación que han experimentado los poetas por las construcciones de la razón crítica" (Paz 1974: 63). 
Amilburu, María G. (2010). "Ernst Cassirer”, en <www.philosophica.info/voces/cassirer/Cassirer.html>, consultado por última vez el 16 de octubre del 2019.

BLOOM, Harold (1977). La angustia de las influencias. Caracas, Monte Ávila Editores. COPLeston, Frederick (1962). A History of Philosophy, vol. 2, parte II. New York, Image Books.

Ferraris, Mauricio (2002). Historia de la hermenéutica. México, Siglo XXI.

FreUd, Sigmund (1973 [1917]). Duelo y melancolía. Obras completas, tomo II, trad. Luis López-Ballesteros y de Torres. Madrid, Biblioteca Nueva.

Freud, Sigmund (1973). Totem y tabú. Obras completas. Madrid, Biblioteca Nueva, Tomo II, trad. Luis López-Ballesteros y de Torres. Madrid, Biblioteca Nueva.

GADAmer, Hans Georg (2007). Verdad y método. Salamanca, Ediciones Sígueme.

GARAGAlZA, Luis (2014). "Tras las huellas de Hermes: la hermenéutica simbólica como contribución a los estudios del imaginario", Cadernos de Educaçao, núm. 48: 65-87.

HoEzen Polack, Benjamin (2002). "Lacan y el otro". A parte rei: revista de filosofía, núm. 21: 1-13.

KozLIK, Adolf (1972). El capitalismo popular. México, Siglo XXI.

LÉvinAS, Emmanuel (2002). Algunas reflexiones sobre la filosofía del hitlerismo. México, Fondo de Cultura Económica.

LÉVINAS, Emmanuel (2012). Totalidad e infinito. Salamanca, Ediciones Sígueme.

Nietzsche, Friederich (1980). Kritische Studienausgabe, vol 12. Munich, Deutschen Taschenbuch Verlags y De Gruyter.

Palacio, Marta (2013). "La posición de Lévinas en el giro hermenéutico”. Areté. Revista de Filosofía, vol. 25, núm. 1: 133-152.

Patxi, Lanceros (2006). "Mimesis/Poiesis”, Diccionario de Hermenéutica, dir. Andrés Ortiz-Osés y Patxi Lanceros. Bilbao, Universidad de Deusto.

Paz, Octavio (1974). Los hijos del limo. Barcelona, Seix Barral.

Uxía RIVAS, Marías (1996). "Frege y Pierce: en torno al signo y su fundamento". Anuario Filosófico, vol. 29, núm. 3: 1211-1224.

\section{Verónica Volkow}

Escritora y académica, cuenta con múltiples publicaciones. Actualmente trabaja como investigadora titular en el Instituto de Investigaciones Filológicas de la UNAM. Tiene maestría y doctorado en Literatura Comparada y una segunda maestría en Historia del Arte en la UNAM. Ha sido en varias ocasiones becaria del Sistema Nacional de Creadores y actualmente es miembro del SNI. En 2004 recibió el Premio Pellicer por el poemario Oro del viento, Editorial Era, y en 2005 el Premio José Revueltas de Ensayo Literario por El Retrato de Jorge Cuesta, Siglo XXI Editores. Entre sus últimos libros se encuentra: Dos cielos, dos soles; imágenes de la totalidad a finales del XVII novohispano, México, IIFL, 2014. 